\title{
Zno Nanostructures Via Hydrothermal Synthesis on Atomic Layer Deposited Seed-Layers
}

\author{
Anatolii Orlov, Veronika Ulianova, \\ Oleksandr Bogdan, Genadzi Pashkevich \\ Research Institute "Applied Electronics" \\ National Technical University of Ukraine "KPI" \\ Kyiv 03056 Ukraine \\ v.ulianova@gmail.com
}

\author{
Necmi Biyikli, Eda Goldenberg, Ali Haider \\ National Nanotechnology Research Center (UNAM) \\ Institute of Materials Science and Nanotechnology \\ Bilkent University, Bilkent, Ankara 06800 Turkey \\ biyikli@unam.bilkent.edu.tr
}

\begin{abstract}
Abstrac t- The original results of two different types of $\mathrm{ZnO}$ nanostructures grown via hydrothermal synthesis on $\mathrm{ZnO}$ seedlayers coated by atomic layer deposition process on Si substrates were presented. Scanning electron microscopy and X-ray diffractometry were used for the analysis of resulting nanostructured $\mathrm{ZnO}$ samples. The influence of annealing on crystal properties of the $\mathrm{ZnO}$ nanostructures was shown. It was ascertained that solution composition had a significant influence on the morphology of nanostructures and post-growth annealing modified the crystal properties of nanostructures.
\end{abstract}

Keywords - seed-layer, ZnO nanostructures, atomic layer deposition, hydrothermal synthesis, zinc acetate, zinc nitrate

\section{INTRODUCTION}

Nanostructured $\mathrm{ZnO}$ is a promising material for the novel electronic devices development due to its wurtzite crystal structure, wide direct band gap and high exciton binding energy. $\mathrm{ZnO}$ can be manufactured in a controlled manner to produce nanostructures with a uniform size, distribution and orientation by vapor-phase synthesis [1], pulsed laser deposition method [2], electrochemical method [3], hydrothermal method [4-5] etc. Hydrothermal method has many advantages when compare to the most common vaporphase synthesis, such as low-cost, low temperature, scalability and ease handling.

Generally, there are two main steps in nanostructured $\mathrm{ZnO}$ growth by hydrothermal method: (1) preparation of a seedtextured $\mathrm{ZnO}$ thin layer and (2) the nanostructured $\mathrm{ZnO}$ array growth. For the first step magnetron sputtering [6], sol-gel method [7], atomic layer deposition (ALD) [8] can be applied. Sol-gel technique is attractive due to the ability to conveniently synthesize the films with required properties for a given application almost on all types of substrates. The length and diameter of the nanowires are highly dependent on the crystalline properties (i.e., grain size) of the seed-layer films. Typical pre-seeding sol-gel method includes thermal decomposition of the precursor; spin coating of sol-gel solution and annealing at certain temperature to improve $\mathrm{ZnO}$ particles adhesion to the substrate [7]. The type and concentration of precursor, annealing temperature have an obvious influence on the surface structure of $\mathrm{ZnO}$ films. On the other hand, ALD technique is known to be unique in terms of sub-nm thickness control and uniformity and provides an ideal performance for seed-layer growth.

The current study is aimed to the ascertainment of the most suitable process parameters for obtaining of $\mathrm{ZnO}$ nanorods with certain morphometric characteristics which define physicochemical properties of the material. This research was devoted to the investigation of solution type and post-growth annealing influence on $\mathrm{ZnO}$ nanostructures synthesized via hydrothermal method on $\mathrm{ZnO}$ seed-layers formed by ALD process.

\section{MATERIALS AND METHODS}

$\mathrm{ZnO}$ seed-layer deposition on pre-cleaned Si (100) wafers was carried out at $\sim 200^{\circ} \mathrm{C}$ in a Savannah S100 ALD reactor (Ultratech/CambridgeNanotech Inc.). Diethylzinc (DEZn) and water $\left(\mathrm{H}_{2} \mathrm{O}\right)$ were utilized as $\mathrm{Zn}$ and $\mathrm{O}$ precursors, respectively. $\mathrm{N}_{2}$ was used as the carrier/purge gas at a flow rate of $\sim 20 \mathrm{sccm}$. One ALD cycle consisted of the following steps: $\mathrm{H}_{2} \mathrm{O}$ pulse $(0.015 \mathrm{~s}) / \mathrm{N}_{2}$ purge $(20 \mathrm{sccm}, 10 \mathrm{~s}) / \mathrm{DEZn}$ pulse $(0.015 \mathrm{~s}) / \mathrm{N}_{2}$ purge $(20 \mathrm{sccm}, 10 \mathrm{~s}) .400$ cycles were applied to achieve a $\mathrm{ZnO}$ seed-layer thickness of $\sim 45 \mathrm{~nm}$, which was confirmed through spectroscopic ellipsometer measurements.

Two types of starting materials were used to determine the solution composition for growing perfectly aligned and uniform $\mathrm{ZnO}$ nanostructures. The equimolar (1:1) mixed solution of analytically pure zinc acetate $\left(\mathrm{Zn}\left(\mathrm{COOH}_{3}\right)_{2}\right)$ for the first group of samples and zinc nitrate $\left(\mathrm{Zn}\left(\mathrm{NO}_{3}\right)_{2}\right.$ for the second group and hexamethylenetetramine (HMT) $\mathrm{C}_{6} \mathrm{H}_{12} \mathrm{~N}_{4}$ for both were used to perform the hydrothermal synthesis. The chemicals were solved in deionized water, resulting in a transparent solution under magnet stirring for $5 \mathrm{~min}$ at room temperature. As-pretreated Si substrates were immersed and suspended in the mixed solution. The growth of $\mathrm{ZnO}$ nanorods was carried out by heating the reaction solution from room temperature to $90^{\circ} \mathrm{C}$ and then kept for $90 \mathrm{~min}$ for the first group and for $120 \mathrm{~min}$ for the second without any stirring. The as-grown samples were rinsed with deionized water for several times and dried in air at room temperature before characterization. The resulting samples were annealed at $350^{\circ} \mathrm{C}$ in air for 60 min to study the influence of annealing on the crystal structure. 


\section{IEEE 35th International Conference on Electronics and Nanotechnology (ELNANO)}

Scanning electron microscopy (SEM, Hitachi S4800) was used to examine the morphology. The structural properties of the as-prepared $\mathrm{ZnO}$ nanorods were characterized by X-ray diffractometry (XRD, Rigaku ULTIMA IV) before and after annealing in asymmetric mode, which allows obtaining information about the crystalline phase of the surface layer, substrate in this measurement mode makes a minimum contribution to the resulting X-ray spectrum.

\section{RESULTS AND DISCUSSION}

Process parameters of the chemical materials synthesis, substrate preconditioning and seed-layer growth significantly affect the quality and the shape of the obtained structures. The seed-layer deposition was carried out to provide the growing centers and bonding interface with substrates.

The characterization of the deposited $\mathrm{ZnO}$ seed-layer on $\mathrm{Si}$ substrate by ALD technique is presented in the Fig. 1 and 2 . The SEM image of seed-layer (Fig. 1, a) illustrates high quality regular smooth $\mathrm{ZnO}$ seed-layer, the thickness of the layer is about $45 \mathrm{~nm}$.

The crystalline phase of the seed-layer was assessed by Xray diffractometry in asymmetric mode (Fig.2). The intensive diffraction peaks corresponded to the (100), (002) and (101) planes of $\mathrm{ZnO}$, which clearly indicates the polycrystalline form of the thin $\mathrm{ZnO}$ seed-layer.

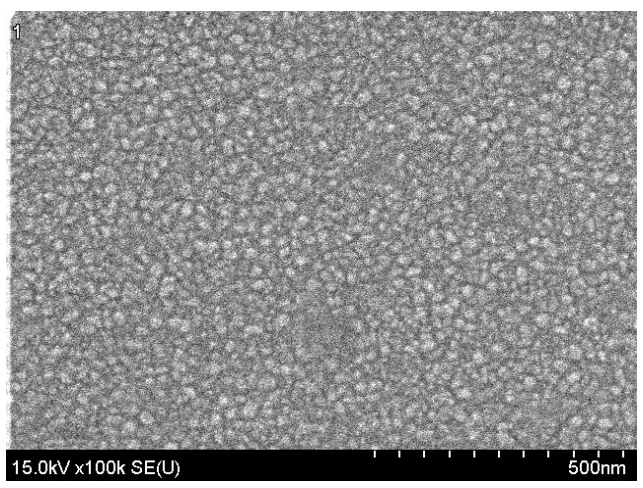

a

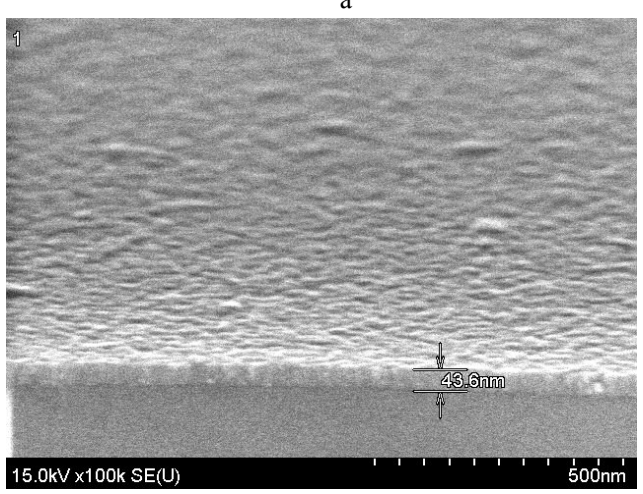

$\mathrm{b}$

Fig. 1. Top-view (a) and cross-sectional (b) SEM images of $\mathrm{ZnO}$ seed-layer formed byALD process.

The shape and geometric characteristics of synthesized structures were studied by SEM analysis. The results of SEM for the first group of samples (Fig. 3) show that synthesized in zinc acetate/hexamethylenetetramine solution at $90^{\circ} \mathrm{C}$ on $\mathrm{ZnO}$ seed-layer consisted of densely packed flake-shape particles; the thickness of the film was about $460 \mathrm{~nm}$. From the SEM for the second group of samples (Fig. 4) it can be seen that nanorod structures with diameters of about $60-80 \mathrm{~nm}$ and length of about $550 \mathrm{~nm}$ were formed in zinc nitrate/ hexamethylenetetramine solution at $90^{\circ} \mathrm{C}$ on $\mathrm{ZnO}$ seed-layer.

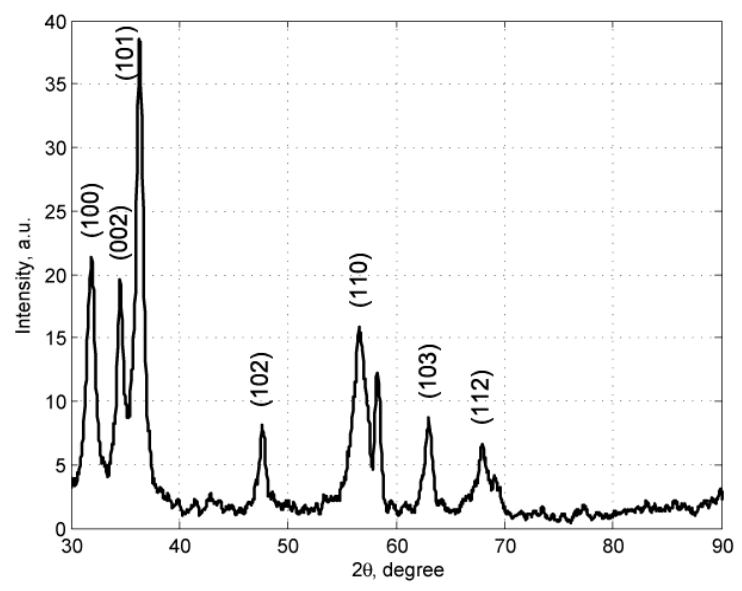

Fig. 2. XRD patterns of $\mathrm{ZnO}$ seed-layer formed by ALD process.

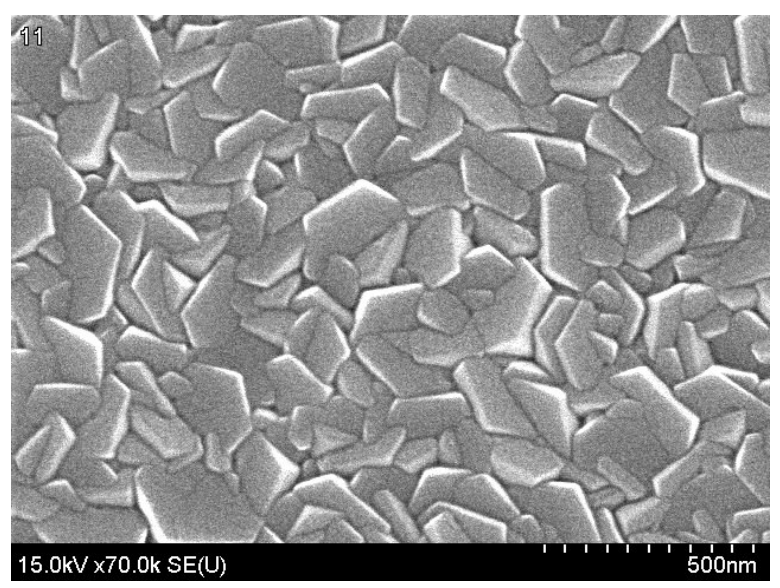

a

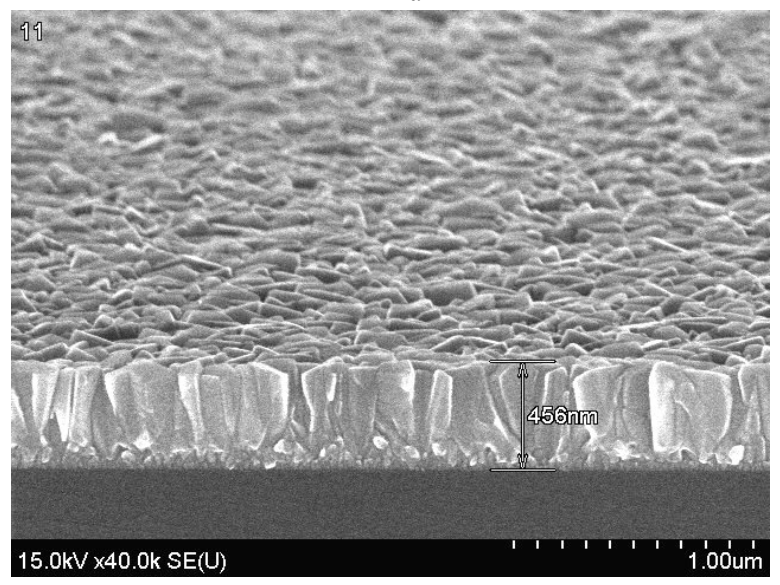

b

Fig. 3. Top-view (a) and cross-sectional (b) SEM images of $\mathrm{ZnO}$ nanostructured film obtained from zinc acetate based solution. 
2015 IEEE 35th International Conference on Electronics and Nanotechnology (ELNANO)

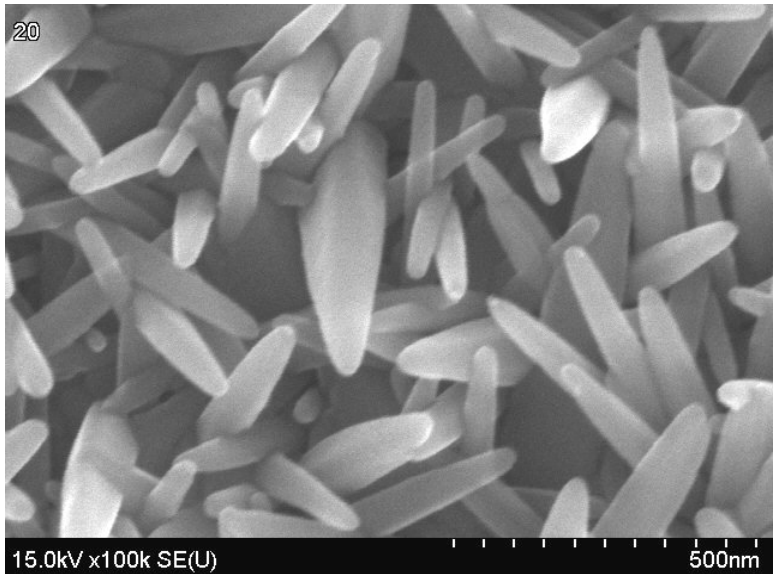

a

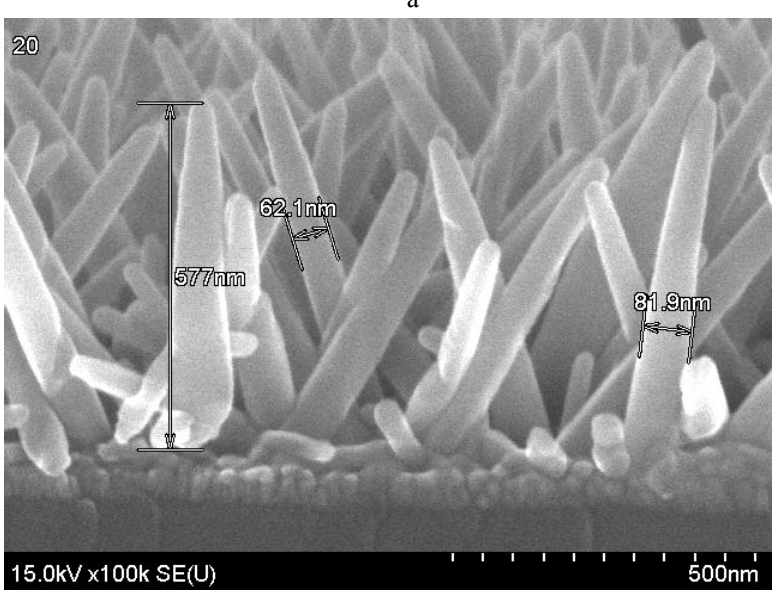

b

Fig. 4. Top-view (a) and cross-sectional (b) SEM images of $\mathrm{ZnO}$ nanostructured film obtained from zinc nitrate based solution.

The crystalline phase of the flake-shape particles before and after annealing was assessed by X-ray diffractometry in asymmetric mode as well as the crystalline phase of the $\mathrm{ZnO}$ nanorods (Fig. 5). The most intensive diffraction peak corresponds to the (002) plane of wurtzite $\mathrm{ZnO}$, other peaks corresponding to (100), (101), (102), (103) and (112) planes are pronounced with relatively lower intensities.

After annealing process, the diffraction peaks are sharpened and enhanced for both samples. The intensity of the reflexes increased twice after annealing, suggesting that the thermal treatment improved the crystallization of the $\mathrm{ZnO}$ nanoparticles.

It was found that XRD patterns of $\mathrm{ZnO}$ nanostructures before and after annealing showed the same form. This indicates that $\mathrm{ZnO}$ films prepared by hydrothermal method showed a good c-axis orientation perpendicular to the substrate and also means that orientation of prepared $\mathrm{ZnO}$ films was not destroyed after annealing. The demonstrated diffraction peaks are in good agreement with standard diffraction peaks of hexagonal wurtzite phase $\mathrm{ZnO}$ (PDF Card No.: 01-075-6445) for both samples. The diffraction angle of diffraction peak corresponding to the planes of hexagonal $\mathrm{ZnO}$ for both groups after annealing became closer to standard XRD spectrum (Tables I and II).

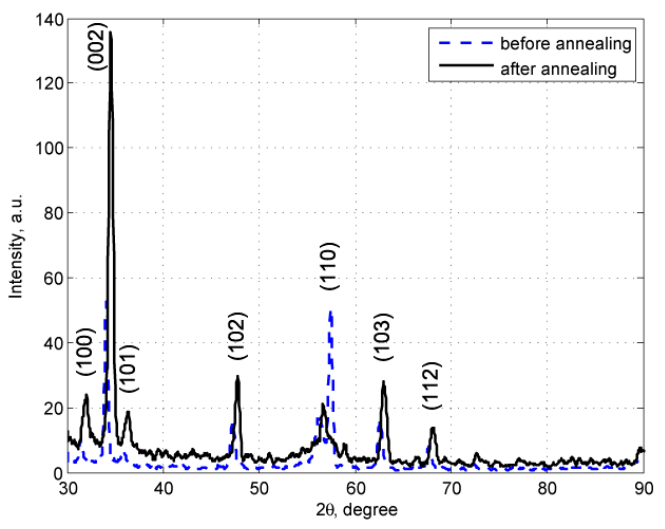

a

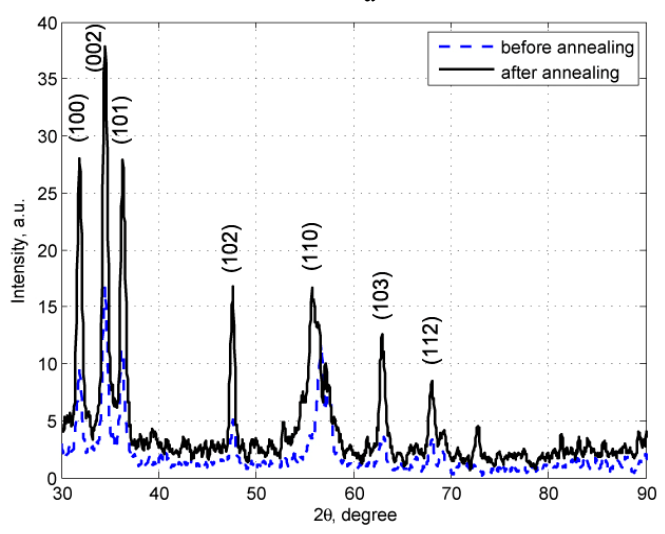

b

Fig. 5. XRD patterns of $\mathrm{ZnO}$ nanostructured film obtained from zinc acetate (a) and zinc nitrate (b) based solution before and after annealing.

TABLE I. PEAK LIST OF THE XRD PATTERNS OF ZNO NANORODS FROM THE FIRST GROUP

\begin{tabular}{|l|l|l|l|l|l|}
\hline \multicolumn{3}{|c|}{ 20, degree } & \multicolumn{3}{c|}{$\begin{array}{c}\text { Miller } \\
\text { indices }\end{array}$} \\
\hline $\begin{array}{c}\text { Card No.: } \\
\text { 01-075-6445 }\end{array}$ & \multicolumn{1}{|c|}{$\begin{array}{c}\text { before } \\
\text { annealing }\end{array}$} & $\begin{array}{c}\text { after } \\
\text { annealing }\end{array}$ & $\boldsymbol{h}$ & $\boldsymbol{k}$ & $\boldsymbol{l}$ \\
\hline 31.8193 & 31.36 & 31.99 & 1 & 0 & 0 \\
\hline 34.4664 & 34.05 & 34.54 & 0 & 0 & 2 \\
\hline 36.1904 & 36.12 & 36.33 & 1 & 0 & 1 \\
\hline 47.5678 & 47.33 & 47.79 & 1 & 0 & 2 \\
\hline 56.7814 & 56.21 & 56.60 & 1 & 1 & 0 \\
\hline 62.7262 & 62.54 & 62.95 & 1 & 0 & 3 \\
\hline 67.8592 & 67.69 & 68.08 & 1 & 1 & 2 \\
\hline
\end{tabular}

Calculated lattice constants of the synthesized $\mathrm{ZnO}$ nanostructures samples before and after annealing and standard values are presented in the Tables III and IV.

From the analysis of obtained results it could be seen that after annealing lattice constants became closer to the standard values.

Crystallite sizes calculated by Williamson-Hall method increased from $15.9 \mathrm{~nm}$ to $19.2 \mathrm{~nm}$ for the first group and from $10.2 \mathrm{~nm}$ to $16.2 \mathrm{~nm}$ for the second. This can be viewed as the merging process of $\mathrm{ZnO}$ nanoparticles induced from thermal 


\section{IEEE 35th International Conference on Electronics and Nanotechnology (ELNANO)}

annealing. In the case of $\mathrm{ZnO}$ nanostructures, at high temperature the merging process of the zinc or oxygen defects occurred at the grain boundaries by stimulating the coalescence of more grains during annealing.

TABLE II. PEAK LIST OF THE XRD PATTERNS OF ZNO NANORODS FROM THE SECOND GROUP

\begin{tabular}{|l|l|l|l|l|l|}
\hline \multicolumn{3}{|c|}{ 20, degree } & \multicolumn{3}{c|}{$\begin{array}{c}\text { Miller } \\
\text { indices }\end{array}$} \\
\hline $\begin{array}{c}\text { Card No.: } \\
\text { 01-075-6445 }\end{array}$ & \multicolumn{1}{|c|}{$\begin{array}{c}\text { before } \\
\text { annealing }\end{array}$} & $\begin{array}{c}\text { after } \\
\text { annealing }\end{array}$ & $\boldsymbol{h}$ & $\boldsymbol{k}$ & $\boldsymbol{l}$ \\
\hline 31.8193 & 31.94 & 31.82 & 1 & 0 & 0 \\
\hline 34.4664 & 34.48 & 34.48 & 0 & 0 & 2 \\
\hline 36.1904 & 36.16 & 36.32 & 1 & 0 & 1 \\
\hline 47.5678 & 48.02 & 47.58 & 1 & 0 & 2 \\
\hline 56.7814 & 56.65 & 56.36 & 1 & 1 & 0 \\
\hline 62.7262 & 63.27 & 62.86 & 1 & 0 & 3 \\
\hline 67.8592 & 68.02 & 68.10 & 1 & 1 & 2 \\
\hline
\end{tabular}

TABLE III. LATTICE CONSTANTS OF THE SYNTHESIZED SAMPLES FROM THE FIRST GROUP

\begin{tabular}{|c|l|l|l|}
\hline & \multicolumn{1}{|c|}{$\mathbf{a}$} & \multicolumn{1}{c|}{ b } & \multicolumn{1}{c|}{ c } \\
\hline $\begin{array}{c}\text { Card No.: } \\
\text { 01-075-6445 }\end{array}$ & 3.2494 & 3.2494 & 5.2038 \\
\hline $\begin{array}{c}\text { before } \\
\text { annealing }\end{array}$ & 3.271396 & 3.271396 & 5.231784 \\
\hline after annealing & 3.243334 & 3.243334 & 5.189394 \\
\hline
\end{tabular}

TABLE IV. LATTICE CONSTANTS OF THE SYNTHESIZED SAMPLES FROM THE SECOND GROUP

\begin{tabular}{|c|l|l|l|}
\hline & \multicolumn{1}{|c|}{ a } & \multicolumn{1}{c|}{ b } & \multicolumn{1}{c|}{ c } \\
\hline $\begin{array}{c}\text { Card No.: } \\
\text { 01-075-6445 }\end{array}$ & 3.2494 & 3.2494 & 5.2038 \\
\hline $\begin{array}{c}\text { before } \\
\text { annealing }\end{array}$ & 3.244255 & 3.244255 & 5.181704 \\
\hline after annealing & 3.253413 & 3.25413 & 5.196336 \\
\hline
\end{tabular}

\section{CONCLUSION}

The original results of $\mathrm{ZnO}$ nanostructures hydrothermal synthesis from two different solutions on $\mathrm{ZnO}$ seed-layer obtained by ALD process on Si substrates were presented. The type of starting material for the solution preparation defined the morphology of the formed structures.

Thus, zinc acetate based solution allowed obtaining of dense nanostructured film composed of flake-shape particles, while nanorods structures were formed from the zinc nitrate based solution. The influence of annealing process on crystal properties of the $\mathrm{ZnO}$ nanostructures was shown.

Post-growth thermal treatment at relatively low temperature could be the main approach to further improvement of the $\mathrm{ZnO}$ nanostructured films crystal properties due to the decrease of the defects. From XRD spectrum of the samples the lattice constants and crystallite sizes of $\mathrm{ZnO}$ were verified.

\section{REFERENCES}

[1] M. H. Huang, Y. Y. Wu, H. Feick, N. Tran, E. Weber, P. D. Yang, "Catalytic growth of zinc oxide nanowires by vapor transport," Adv. Mater. 13, 2001, pp. 113-116.

[2] Y. Sun, G. M. Fuge, M. N. R. Ashfold, "Growth of aligned $\mathrm{ZnO}$ nanorod arrays by catalyst-free pulsed laser deposition methods," Chem. Phys. Lett. 396, 2004, pp. 21-26.

[3] A. Orlov, V. Ulianova, Yu. Yakimenko, O. Bogdan, G. Pashkevich, "Synthesis of ZnO Nanorods for Acoustic Wave Sensor," 2013 IEEE XXXIII International Scientific Conference Electronics and Nanotechnology (ELNANO), Kyiv, 2013, pp. 25-27.

[4] P.S. Kumar, A.D. Raj, D. Mangalaraj; D. Nataraj "Growth and characterization of $\mathrm{ZnO}$ nanostructured thin films by a two-step chemical method," Appl. Surf. Sci., vol. 255, 2008, pp. 2382-2387.

[5] A. Orlov, V. Ulianova, Yu. Yakimenko, O. Bogdan, G. Pashkevich, "Influence of Process Temperature on ZnO Nanostructures Formation," 2014 IEEE XXXIII International Scientific Conference Electronics and Nanotechnology (ELNANO), Kyiv, 2014, pp. 51-53.

[6] P. F. Carcia, R. S. McLean, M. H. Reilly, "Transparent $\mathrm{ZnO}$ thin-film transistor fabricated by rf magnetron sputtering," Appl. Phys. Lett, 82(7), 2003, pp. 1117-1119.

[7] S. Ilican, Y. Caglar, M. Caglar, "Preparetion and characterization of $\mathrm{ZnO}$ thin films by sol-gel spin coating method," Journal of optoelectronics and advanced materials, vol.10, No.10, October 2008, pp. 2578-2583.

[8] F. Solis-Pomar, E. Martinez, M. Melendrez, E. perez-Tijerina, "Growth of vertically aligned $\mathrm{ZnO}$ nanorods using textured $\mathrm{ZnO}$ films," Nanoscale Research Letters, 2011, 6:524, 11 p. 